\title{
Towards a Mechanistic Understanding of Rheological Behaviour of Water-in-Oil Emulsion: Roles of Nanoparticles, Water Volume Fraction and Aging Time
}

\author{
Amin Pajouhandeh ${ }^{\mathrm{a}, \mathrm{b}, \boldsymbol{}}$, Ali Kavousi ${ }^{\mathrm{a}, \mathrm{b}}$, Mahin Schaffie and Mohammad Ranjbar ${ }^{\mathrm{a}}$ \\ ${ }^{a}$ Department of Petroleum Engineering, Shahid Bahonar University of Kerman, Kerman, Iran. \\ ${ }^{b}$ Young Researchers Society, Shahid Bahonar University of Kerman, Iran.
}

Received 29 July 2015, revised 29 September 2015, accepted 8 November 2015.

\begin{abstract}
The viscosity of water-oil emulsions plays an important role in oil production and transportation. The objective of this study was to improve the basic understanding of the influence of nanoparticles on the viscosity of water-in-oil emulsions. Using crude oil and different industrial nanomaterials, the droplet size distribution, droplet mean size, and rheological models of emulsions were investigated. Experimental results show that the addition of nanoparticles increases the crude oil viscosity; however, the Newtonian flow behaviour of oil is not affected by nanoparticles. It is observed that the viscosity of crude oil increased from 36.5 to $49 \mathrm{cP}$ when the nanoparticle concentration was elevated from 0 to $0.1 \mathrm{wt} \%$. From the results of rheological experiments, it can be concluded that the influence of nanoparticles on the emulsion viscosity is mainly affected by the type and amount of nanoparticles, water/oil-ratio and aging time. Mean droplet diameter decreased from 5.68 to 4.11 micrometre when $0.1 \mathrm{wt} \%$ nanoparticles were added to emulsion. The results also suggest that the properties of stabilized water-in-oil emulsions are significantly time-dependent, and the droplet size and viscosity of emulsions is reduced by time. Most of previously published correlations have huge errors and could not precisely predict the apparent viscosities of non-solid stabilized and solid-stabilized emulsions. None of the previously utilized equations did ever consider the effect of added solids to the emulsion.
\end{abstract}

KEYWORDS

Emulsion, viscosity, nanoparticle, aging time, droplet size.

\section{Introduction}

An emulsion is a mixture of two or more liquids that are normally immiscible. Emulsions that are used in practice normally contain an emulsifying agent (surfactant) ${ }^{1-5}$ Emulsions are normally divided into two groups, namely water-in-oil or oil-in-water emulsions. Water-in-oil emulsions may be encountered at all stages in the petroleum industry such as drilling fluids, production, and transportation. ${ }^{3,6,7}$ These types of emulsions have viscosities that are substantially higher than crude oil. ${ }^{8}$ On the other hand, due to their higher viscosity and lower interfacial tension, water-in-oil emulsions can be used as a cheaper alternative to polymers during different oil production operations including enhanced oil recovery (EOR) and water control. ${ }^{9,10}$

Emulsions are thermodynamically unstable. ${ }^{11}$ Emulsions that are stabilized by surfactants are usually used for EOR projects. Solid particles may also be added to the oil or water prior to emulsification for further stabilization of the emulsion. Solids in emulsions cover the droplet surface coalescence. ${ }^{12,13}$ Performance of this particle as a stabilizer depends on the particle size, interparticle interactions and particles of oil and water contact angle. Hydrophilic particles with contact angle less than $90^{\circ}$ stabilize oil-in-water emulsions while hydrophobic particles with contact angle more than $90^{\circ}$ stabilize water-in-oil emulsions..$^{14}$

One of the most important properties of emulsions is their rheology. In fact, viscosity plays a key role in simulation and prediction of different oil production operations. ${ }^{15-17}$ Therefore, it is necessary to have a better understanding of the viscosity of water-in-oil or oil-in-water emulsions which contain fine solids. * To whom correspondence should be addressed. E-mail: a.pajouhandeh@gmail.com
Viscosity of emulsions are affected by several parameters such as temperature, dispersed phase fraction, average droplet size, droplet size distribution, continuous phase viscosity, nature and concentration of emulsifying agents, solid concentration, conditions of mixing, stirring time, mixing devices, aging time, pressure, etc. $^{11,18-21}$

Solids used as emulsion stabilizers were first presented in 1907 by Pickering. ${ }^{22}$ In 1991, Yan et al. studied the rheological properties of oil-in-water emulsions. The results suggest that the viscosity of solid stabilized emulsions varies with solid shape and solid size. ${ }^{23}$ In 2001, Yaghi et al. demonstrated that the viscosity of emulsions varies as the hydrophobicity of nanoparticles changes. ${ }^{24}$ In 2003, Yaghi showed that the relative viscosity of water-in-oil emulsions in the presence of silica varies with solids concentration, oil volume fraction, shear rate and oil viscosity. ${ }^{25}$ In 2010, Simon et al. studied the rheological properties of emulsions stabilized by Aerosil R7200, Aerosil R972 and the mixture of Aerosil R7200 and R972. It was shown that the viscosity of emulsions decreases with increasing the Aerosil R972 concentration in oil-in-water emulsions. ${ }^{14}$ In 2012 , Keleşoğlu et al. characterized the water-in-oil emulsions by means of rheology, droplet size, and laminar flow in pipeline. The results indicated that with increasing the dispersed phase volume fraction, the mean droplet size and emulsion viscosity increases. ${ }^{26}$ Filho et al. reported that the water-in-oil emulsion droplet size of a crude oil containing $0.79 \% \mathrm{~m} / \mathrm{m}$ of asphaltenes increases after 60 days of aging. ${ }^{19} \mathrm{In}$ 2013, Zhang et al. carried out experiments on the apparent viscosity of oil-water emulsion. They reported that the viscosities of emulsions studied are significantly influenced by their dispersed 
phase volume fraction, stirring time and emulsifying agent. Zhang et al. divided the apparent viscosity models into three categories, namely linear, exponential and power models. ${ }^{18} \mathrm{In}$ 2015, Sharma et al. studied the viscoelastic properties of oil-inwater emulsions stabilized by surfactant-polymers and nanoparticle-surfactant-polymers. The results indicated that both the pressure and temperature influenced the storage modulus and loss modulus of the system. ${ }^{27}$ Very recently, Karambeigi et al. made water/oil emulsions using water, diesel and sodium dodecyl sulfate. Prepared emulsions showed shear thinning behaviour. Core-flood test results illustrated the non-Newtonian emulsions improved sweep efficiency during emulsion flooding. ${ }^{28}$

From the information presented above, it can be concluded that only in a few cases the effect of nanoparticles on droplet diameter, droplets size distribution of emulsion was investigated. Furthermore, models to predict solid stabilization of water-in-oil emulsions viscosity were not presented and also the effect of aging time on the viscosity, mean droplet diameter, droplets size distribution and rheological model of nanoparticle stabilized emulsion was not delved. The main aim of this study is to investigate the influence of nanoparticles on the rheological properties, the droplet size distribution and droplet mean diameter of fresh and aged water-in-oil emulsions. One of the problems of previous investigations was that nanoparticles and surfactants were used together (sometimes addition of surfactant or co-surfactant was used), which was solved in this project by using nanoparticles alone.

\section{Materials and Methods}

The experiments were performed using crude oil, nanoparticles and water. Deionized water was used as water phase. Two industrially used nanoparticles, namely NP-I (Aerosil R972 Degussa) and NP-II (Cloisite 20A - Southern Clay Products) were employed. NP-I is fumed silica, treated with DDS (dimethyldichlorosilane). NP-II is natural montmorillonite modified with a quaternary ammonium salt. Both nanoparticles are hydrophobic (contact angle more than $90^{\circ}$ ). Some properties of crude oil, water and nanoparticles are presented in Table 1.

Nanoparticles were added to the crude oil and sonicated with an ultrasonic laboratory processor for $20 \mathrm{~min}$ to disperse aggregation. The nanoparticle concentration in the dispersion varied as $0,0.02,0.05$ and 0.1 by wt $\%$. Subsequently, deionized water was added to the system and dispersed by a mechanical overhead stirrer (IKA, RW20 Digital). The emulsions were prepared with three different water volume fractions (i.e. 5, 10, $20 \mathrm{vol} \%$ ). These nanoparticles were added to decrease the IFT between crude oil and water and consequently more stabilize the prepared emulsion.

Brookfield DV-III Ultra Programmable rheometer with concen- tric cylinder geometry operating by Rheocalc software was used to evaluate the rheological properties of the crude oil as well as nanoparticles suspensions in crude oil, water, and water-in-oil emulsions.

The emulsion viscosity experiments were performed based on a factorial experimental design in DX7 software. Two replicates were utilized to increase the performance. Table 2 illustrates the used variables (factors) and levels in the experimental design.

Table 2 Experimental design level and variable.

\begin{tabular}{lcccc}
\hline \multirow{2}{*}{ Variable } & \multicolumn{4}{c}{ Level } \\
\cline { 2 - 5 } & 1 & 2 & 3 & 4 \\
\hline Nanoparticle & NP-I & NP-II & - & - \\
Nanoparticle concentration/\% & 0 & 0.02 & 0.05 & 0.1 \\
Water volume fraction & 5 & 10 & 20 & - \\
\hline
\end{tabular}

In addition to the viscosity measurements, the microscopic observations of the resulting water-in-oil emulsion were conducted using an Eclipse TE2000-U (Nikon) polarized light microscope. The emulsion microscope images were analyzed for droplet size distribution via AxioVision. Droplet sizes were calculated based on the measurement of the diameters of more than 100 droplets on several micrographs.

One rheological model, namely Power Law (Equation 1$){ }_{,}^{18}$ was used to discuss the rheological behaviour of the discussed systems.

$$
\text { Power Law: } \tau=m(\dot{\gamma})^{n}
$$

Emulsion viscosity is a key parameter for the computational flow simulation. Different models have been developed for predicting the apparent viscosity of emulsions. These models can be classified into the following three categories: (1) linear, (2) power, and (3) exponential function. ${ }^{18}$ The models used in the current study are presented in Table 3 . In these tables, $\eta_{\mathrm{r}}$ is relative viscosity (ratio of apparent viscosity of emulsions to continuous phase viscosity), K shows ratio of dispersed phase viscosity to continuous phase viscosity, $\phi$ denotes dispersed phase volume fraction (in this study, it means water volume fraction), $\phi_{\mathrm{m}}$ expresses maximum packing concentration volume fraction, and $k$ stands for constant parameter which is between 1.28 and 1.30 in Eilers' equation and between 1.35 and 1.91 in Mooney's equation. In this study, the water volume fraction was considered at 5, 10, and $20 \%$. Furthermore, the viscosity of crude oil and emulsion was determined using a rheometer. For modelling the apparent viscosity of water-in-oil emulsions, the viscosity values were taken at $1.22 \mathrm{~s}^{-1}$.As previously mentioned, emulsion's relative viscosity is the ratio of apparent viscosity of emulsions (non-

Table 1 Details on the chemicals and nanoparticles used in the study.

\begin{tabular}{|c|c|c|c|c|c|c|c|c|c|}
\hline Crude oil & ${ }^{\circ} \mathrm{API}$ & Density $/ \mathrm{g} \mathrm{cm}^{-3}$ & $\begin{array}{c}\mathrm{C}_{1} \\
/ \mathrm{Mol} \%\end{array}$ & $\begin{array}{c}\mathrm{C}_{2} \\
/ \mathrm{Mol} \%\end{array}$ & $\begin{array}{c}\mathrm{C}_{3} \\
/ \mathrm{Mol} \%\end{array}$ & $\begin{array}{c}\mathrm{i}-\mathrm{C}_{4} \\
/ \mathrm{Mol} \%\end{array}$ & $\begin{array}{c}\mathrm{n}-\mathrm{C}_{4} \\
/ \mathrm{Mol} \%\end{array}$ & $\begin{array}{l}\mathrm{i}-\mathrm{C}_{5} \\
/ \mathrm{Mol} \%\end{array}$ & $\begin{array}{c}\mathrm{n}^{-\mathrm{C}_{5}} \\
/ \mathrm{Mol} \%\end{array}$ \\
\hline & 29 & 0.9146 & 38.63 & 6.97 & 4.77 & 1.60 & 3.98 & 1.60 & 1.72 \\
\hline \multirow[t]{2}{*}{ Water } & Viscosity/cP) & Density $/ \mathrm{g} \mathrm{cm}^{-3}$ & \multicolumn{2}{|c|}{$\mathrm{pH}$} & & & & & \\
\hline & 1.01 & 0.9978 & \multicolumn{2}{|c|}{6.32} & & & & & \\
\hline \multirow[t]{2}{*}{ Nanoparticle } & NP-I density/g cm ${ }^{-3}$ & NP-II density $/ \mathrm{g} \mathrm{cm}^{-3}$ & \multicolumn{3}{|c|}{ NP-I and NP-II contact angle ${ }^{\circ}$} & & & & \\
\hline & 2.2 & 1.77 & & $>90$ & & & & & \\
\hline
\end{tabular}


Table 3 Models and correlations for the emulsion's relative viscosity.

Type

Authors

Einstein (1906) ${ }^{29}$

Taylor (1932) ${ }^{30}$

Yaron and Gal-Or (1972) ${ }^{31}$

Choi and Schowalter (1975) ${ }^{32}$

Power

$$
\text { Guth and Simha (1936) }{ }^{33}
$$

Eilers (1941) ${ }^{34}$

Roscoe and Brinkman (1952) ${ }^{35,36}$

Krieger and Dougherty (1959) ${ }^{37}$

Phan-Thien and Pham (1997) ${ }^{38}$

Bicerano et al. (1999) ${ }^{39}$

Pal (2000) ${ }^{40}$

Pal (2001) ${ }^{41}$

Exponential

Mooney (1951) ${ }^{42}$

Barnea and Mizrahi (1975) ${ }^{43}$

$\mathrm{Pal}^{41}$
Models and correlations

$$
\begin{gathered}
\eta_{\mathrm{r}}=1+2.5 \varnothing \\
\eta_{\mathrm{r}}=1+\left(\frac{5 \mathrm{~K}+2}{2 \mathrm{~K}+1}\right) \varnothing
\end{gathered}
$$

$$
\eta_{\mathrm{r}}=1+\varnothing\left\{\frac{5.5\left[4 \varnothing^{7 / 3}+10-(84 / 11) \varnothing^{2 / 3}+(4 / \mathrm{K})\left(1-\varnothing^{7 / 3}\right)\right]}{10\left(1-\varnothing^{10 / 3}\right)-25 \varnothing\left(1-\varnothing^{4 / 3}\right)+(10 / \mathrm{K})(1-\varnothing)\left(1-\varnothing^{7 / 3}\right)}\right\}
$$

$$
\eta_{r}=1+\varnothing\left\{\frac{2\left[(5 K+2)-5(K-1) \varnothing^{7 / 3}\right]}{4(K+1)-5(5 K+2) \varnothing+42 K \varnothing^{5 / 3}-5(5 K-2) \varnothing^{7 / 3}+4(K-1) \varnothing^{10 / 3}}\right\}
$$

$$
\eta_{r}=1+2.5 \varnothing+14.1 \varnothing^{2}
$$

$$
\eta_{r}=\left(1+\frac{1.25 \phi}{1-k \phi}\right)^{2}
$$

$$
\eta_{r}=(1-\varnothing)^{-2.5}
$$

$$
\eta_{r}=\left(1-\frac{\varnothing}{\varnothing_{m}}\right)^{-2.5 \varnothing_{m}}
$$

$$
\eta_{r}\left[\frac{2 \eta_{r}+5 K}{2+5 K}\right]^{1.5}=(1-\phi)^{-2.5}
$$

$$
\eta_{r}=\left(1-\frac{\varnothing}{\varnothing_{m}}\right)^{-2}\left[1-0.4\left(\frac{\varnothing}{\varnothing_{m}}\right)+0.34\left(\frac{\varnothing}{\varnothing_{m}}\right)^{2}\right]
$$

$$
\eta_{r}\left[\frac{2 \eta_{r}+5 K}{2+5 K}\right]^{1.5}=\left(1-\frac{\varnothing}{\varnothing_{m}}\right)^{-2}
$$

$$
\eta_{r}\left[\frac{2 \eta_{r}+5 K}{2+5 K}\right]^{1.5}=\left(1-\frac{\varnothing}{\varnothing_{m}}\right)^{-2 \varnothing_{m}}
$$

$$
\begin{gathered}
\eta_{r}=\exp \left(\frac{2.5 \varnothing}{1-k \varnothing}\right) \\
\eta_{r}=C\left(\frac{\frac{2}{-} C+K}{C+K}\right), C=\exp \left[\frac{5 \varnothing}{3(1-\varnothing)}\left(\frac{0.4+K}{1+K}\right)\right] \\
\eta_{r}\left[\frac{2 \eta_{r}+5 K}{2+5 K}\right]^{1.5}=\exp \left(\frac{2.5 \varnothing}{1-\frac{\varnothing}{\varnothing}}\right)
\end{gathered}
$$


stabilized and solid-stabilized) to continuous phase viscosity (crude oil viscosity for water-in-oil emulsion). To investigate the accuracy and performance of the models, the statistical error including average percentage relative error (APRE), average absolute percentage relative error (AAPRE), and error distribution curve were used for the data analysis.

\section{Results and Discussion}

\subsection{Crude Oil}

The flow behaviour of crude oil and the nanoparticles suspensions in crude oil were investigated at four different temperatures $\left(20,30,40\right.$, and $\left.50^{\circ} \mathrm{C}\right)$. The Power Law model (Equation 1 was fitted to the experimental data at various temperatures by means of multiple non-linear regressions and least square technique. The calculated parameters are listed in Table 4. According to the results presented in this table, the Power Law model gave a very good regression correlation coefficient $\left(R^{2}>0.999\right)$. It is evident that the crude oil and the nanoparticles suspensions in crude oil behaved as a Newtonian fluid over the whole range of temperature and nanoparticle concentration ( $n$ is equal to one). Moreover, this table illustrates the consistency index $(m)$ of the Power Law model was higher at lower temperatures.

Figure 1 shows the crude oil viscosity as a function of shear rate and temperature for the samples with and without nanoparticles. Comparison of Fig. 1 and Table 4 show that the addition of nanoparticles increased the crude oil viscosity; however, the Newtonian flow behaviour of oil was not affected by nanoparticles. Using the suspension viscosity model such as Einstein, ${ }^{29}$ Taylor, ${ }^{39}$ etc., could prove the viscosity increment. The viscosity increased significantly with the nanoparticle content, which could be probably due to strong aggregation of the nanoparticles. Also, the viscosity of crude oil and nanoparticles suspensions in crude oil decreased with temperature increase. It can be observed that the viscosity of crude oil was reduced from 36.5 to $9.6 \mathrm{cP}$ when the temperature was elevated from 20 to $50^{\circ} \mathrm{C}$. By increasing temperature, the intermolecular bonds between adjacent layers broke.

\subsection{Water-in-oil Emulsion}

From the results of samples microscopy and drop tests, the type of the solid-free and solid-stabilized emulsions was determined to be water-in-oil. NP-I (Aerosil R972) and NP-II (Cloisite 20A) are hydrophobic particles; therefore, they form water-in-oil emulsions. ${ }^{14}$ Indication of emulsion stability was given by the bottle test method. In this method, the extent of phase separa-
Table 4 Power Law constants for crude oil and nanoparticle suspensions in crude oil.

\begin{tabular}{|c|c|c|c|c|}
\hline \multirow{2}{*}{$\begin{array}{l}\text { Temperature } \\
{ }^{\circ} \mathrm{C}\end{array}$} & \multirow{2}{*}{$\begin{array}{l}\text { Nanoparticle } \\
\text { concentration } \\
\quad / \text { wt } \%\end{array}$} & \multicolumn{3}{|c|}{ Power Law model } \\
\hline & & $m$ & $n$ & $R^{\mathrm{I}}$ \\
\hline 20 & 0 & 0.3561 & 0.999 & 0.9999 \\
\hline 30 & 0 & 0.1870 & 0.997 & 0.9999 \\
\hline 40 & 0 & 0.1181 & 1.014 & 0.9999 \\
\hline 50 & 0 & 0.0860 & 1.015 & 0.9999 \\
\hline 20 & 0.02 (NP-II) & 0.4593 & 1.010 & 0.9998 \\
\hline 30 & 0.02 (NP-II) & 0.2303 & 0.999 & 0.9999 \\
\hline 40 & 0.02 (NP-II) & 0.1363 & 1.190 & 0.9999 \\
\hline 50 & 0.02 (NP-II) & 0.1024 & 1.009 & 0.9998 \\
\hline 20 & 0.05 (NP-II) & 0.4674 & 1.005 & 0.9998 \\
\hline 30 & 0.05 (NP-II) & 0.2324 & 1.007 & 0.9999 \\
\hline 40 & 0.05 (NP-II) & 0.1469 & 1.008 & 0.9998 \\
\hline 50 & 0.05 (NP-II) & 0.1079 & 1.020 & 0.9997 \\
\hline 20 & 0.1 (NP-II) & 0.5307 & 0.983 & 0.9999 \\
\hline 30 & 0.1 (NP-II) & 0.2611 & 0.984 & 0.9999 \\
\hline 40 & 0.1 (NP-II) & 0.1544 & 1.017 & 0.9993 \\
\hline 50 & 0.1 (NP-II) & 0.1227 & 0.986 & 0.9999 \\
\hline 20 & 0.02 (NP-I) & 0.3801 & 0.991 & 0.9999 \\
\hline 30 & 0.02 (NP-I) & 0.1793 & 1.018 & 0.9997 \\
\hline 40 & 0.02 (NP-I) & 0.1126 & 1.064 & 0.9997 \\
\hline 50 & 0.02 (NP-I) & 0.0911 & 1.074 & 0.9994 \\
\hline 20 & 0.05 (NP-I) & 0.3731 & 1.002 & 0.9999 \\
\hline 30 & 0.05 (NP-I) & 0.1850 & 1.022 & 0.9998 \\
\hline 40 & 0.05 (NP-I) & 0.1128 & 1.048 & 0.9997 \\
\hline 50 & 0.05 (NP-I) & 0.0867 & 1.047 & 0.9998 \\
\hline 20 & 0.1 (NP-I) & 0.4158 & 1.007 & 0.9999 \\
\hline 30 & 0.1 (NP-I) & 0.2183 & 1.010 & 0.9999 \\
\hline 40 & 0.1 (NP-I) & 0.1310 & 1.024 & 0.9998 \\
\hline 50 & 0.1 (NP-I) & 0.1099 & 1.015 & 0.9999 \\
\hline
\end{tabular}

tion with time was monitored. The bottle test showed the emulsions with added NP-I and NP-II were more stable than the solid-free emulsion. Furthermore, an increase in the water cut decreased the stability of emulsions, which was related to the increased expulsion between the droplets and can intensify coalescence and Ostwald ripening. Young-Laplace equation (Equation 2) could prove this result. ${ }^{26}$

$$
\Delta P_{12}=\Delta P_{1}-\Delta P_{2}=2 \gamma_{\text {ow }}\left(\frac{1}{r_{1}}-\frac{1}{r_{2}}\right)
$$

where $\Delta P_{12}$ is the difference in internal pressure between the droplets and $\gamma_{\text {ow }}$ is the interfacial tension. This equation reveals that the pressure inside small droplets is greater than that of the

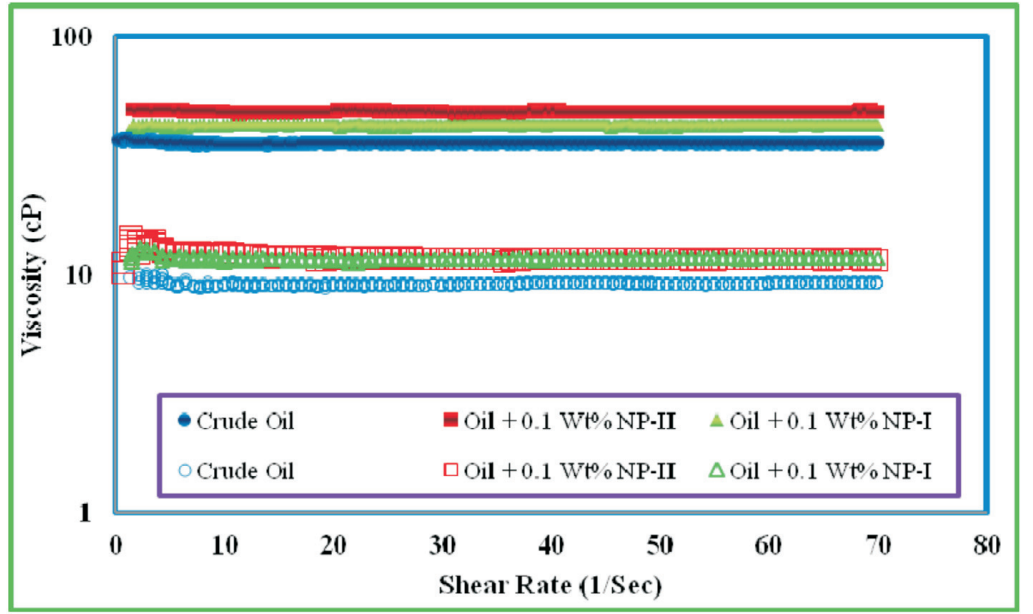

Figure 1 Effects of shear rate and nanoparticles on the viscosity of crude oil (filled symbols: $20^{\circ} \mathrm{C}$; open symbols: $50{ }^{\circ} \mathrm{C}$ ). 
larger ones and, as a result, by increasing the diameter of water droplet with water cut increment, the emulsion stability decreases.

The rheological measurements were carried out immediately and also four days after the sample preparation. All of the experiments were performed at $20^{\circ} \mathrm{C}$ and the effects of water volume fraction, nanoparticle type, and nanoparticle concentration on the rheological properties of the emulsions before and after aging were investigated.

\subsubsection{Fresh Emulsion}

In the first part of this section, the rheological properties of the emulsions, measured directly after preparation (without aging), will be presented.

The Power Law model (Equation 1) was fitted to the experimental data at various volumes of water fractions, nanoparticle types, and nanoparticle concentrations. The calculated parameters are summarized in Table 5, illustrating that the Power Law model had a considerably well regression correlation coefficient $\left(R^{2}>0.988\right)$ for the water-in-oil emulsions at all water volume fractions and nanoparticle concentrations. In some cases, especially at lower volume of water fractions (5 and $10 \%$ ), the rheology of the emulsions differed from the Newtonian behaviour.

Figure 2 illustrates the influences of NP-I and NP-II concentrations on the relative viscosity of water-in-oil emulsions. Figure 2 demonstrates that all the quantities of nanoparticles changed the relative viscosity of water-in-oil emulsions.The emulsion viscosity was increased by the summation in water volume fraction and nanoparticle concentration, except the $20 \%$ stabilized by $0.1 \mathrm{wt} \%$ NP-I. As demonstrated in the figure, the emulsion with the water volume fraction of $10 \%$ stabilized by $0.1 \mathrm{wt} \%$ NP-I had higher viscosity than the others. It was also found that the nanoparticles type and concentration in the emulsion sample play an dominant role in determining its viscosity.

Photomicrographs revealed that the average droplet size of the emulsions increased by enhancing the water volume fraction and also reduced by increasing nanoparticle concentration. Figure $3 a$ displays the typical photomicrographs $(\times 100)$ of water-in-oil emulsions. Table 6 shows the mean droplet diame- ter of the emulsion, illustrating that the water cut had an influence on droplet size. By increasing water cut, the droplet diameter of the emulsion increased, which indicated the droplets could have packed closer. Consequently, the separation distance between water droplets decreased where small droplets occupied the free space between the large ones. ${ }^{6}$ As is apparent from Fig. 3a and Table 6, nanoparticles clearly had an influence on the size of the emulsified water droplets. Added nanoparticles were adsorbed onto the water-oil interface and, then, the surface energy of the system was reduced. Consequently, the established emulsion droplets became smaller. Therefore, the viscosity and stability of the prepared emulsion increased. ${ }^{6,44}$

The droplet diameter distributions of the emulsions are illustrated in Fig. 4a. In the presence of solid particles, the distribution was shifted toward smaller droplets size, which was in collaboration with the microscopic image (Fig. 3a). In other words, the emulsion droplet size distribution attained a narrower range with increasing the nanoparticles concentration. Subsequently, by the addition of nanoparticles, the emulsion droplet diameter distribution changed from bimodal to asymmetric types. In general, emulsions with the smaller size droplets and narrower droplet size distribution are more viscous due to friction increment. ${ }^{45}$

Since the three factors of water volume fraction as well as different types of nanoparticle and nanoparticle concentration were of significance in our investigation, a factorial experimental design was used. Analysis of variance (ANOVA) is a statistical method used to test significant difference between the independent groups on some variables. ${ }^{46}$ The results of the statistical tests (ANOVA) are summarized in Table 7. P-value is the probability of experimental outcome that is used for testing a statistical hypothesis. ${ }^{46}$ In addition, the standard deviation of two replicates is presented in the mentioned table. According to Table 7, water volume fraction, nanoparticle concentration, and the combination of water volume fraction and type of nanoparticle had significant effects $(P<0.05)$ on emulsion viscosity.

Figure 5 shows the average absolute percentage relative error

Table 5 Power Law constants for the water-in-oil emulsions.

\begin{tabular}{|c|c|c|c|c|c|c|c|}
\hline \multirow{2}{*}{$\begin{array}{l}\text { Water volume } \\
\text { fractions }\end{array}$} & \multirow{2}{*}{$\begin{array}{c}\text { Nanoparticles } \\
\text { concentration } \\
\text { /wt } \%\end{array}$} & \multicolumn{3}{|c|}{ Fresh emulsion } & \multicolumn{3}{|c|}{ Aged emulsion } \\
\hline & & $m$ & $n$ & $R^{2}$ & $m$ & $n$ & $R^{2}$ \\
\hline 0.2 & 0 & 0.7404 & 1.009 & 0.9997 & 0.4909 & 1.001 & 0.9999 \\
\hline 0.2 & 0.02 (NP-II) & 1.0300 & 0.981 & 0.9997 & 0.6399 & 0.999 & 0.9999 \\
\hline 0.2 & 0.05 (NP-II) & 1.0190 & 0.991 & 0.9997 & 0.4897 & 1.010 & 0.9999 \\
\hline 0.2 & 0.1 (NP-II) & 1.0140 & 0.979 & 0.9997 & 0.4992 & 1.007 & 0.9999 \\
\hline 0.2 & 0.02 (NP-I) & 0.9222 & 0.985 & 0.9996 & 0.5348 & 1.003 & 0.9999 \\
\hline 0.2 & 0.05 (NP-I) & 0.9928 & 0.965 & 0.9998 & 0.5506 & 1.002 & 0.9998 \\
\hline 0.2 & 0.1 (NP-I) & 0.9277 & 0.980 & 0.9997 & 0.5499 & 1.002 & 0.9999 \\
\hline 0.1 & 0 & 0.4373 & 0.975 & 0.9998 & 0.6615 & 0.905 & 0.9999 \\
\hline 0.1 & 0.02 (NP-II) & 0.7118 & 0.940 & 0.9999 & 0.6403 & 0.956 & 0.9998 \\
\hline 0.1 & 0.05 (NP-II) & 0.5924 & 0.991 & 0.9997 & 0.5288 & 0.968 & 0.9998 \\
\hline 0.1 & 0.1 (NP-II) & 0.7443 & 0.931 & 0.9997 & 0.5666 & 0.941 & 0.9999 \\
\hline 0.1 & 0.02 (NP-I) & 1.2380 & 0.838 & 0.9996 & 1.0960 & 0.817 & 0.9998 \\
\hline 0.1 & 0.05 (NP-I) & 1.3360 & 0.806 & 0.9998 & 0.8249 & 0.904 & 0.9998 \\
\hline 0.1 & 0.1 (NP-I) & 3.0340 & 0.514 & 0.9883 & 1.2320 & 0.796 & 0.9986 \\
\hline 0.05 & 0 & 0.4198 & 1.002 & 0.9998 & 0.5296 & 1.006 & 0.9998 \\
\hline 0.05 & 0.02 (NP-II) & 0.5500 & 0.982 & 0.9997 & 0.5212 & 1.015 & 0.9999 \\
\hline 0.05 & 0.05 (NP-II) & 0.5572 & 0.998 & 0.9995 & 0.5217 & 0.998 & 0.9999 \\
\hline 0.05 & 0.1 (NP-II) & 0.5869 & 0.977 & 0.9996 & 0.5067 & 1.000 & 0.9999 \\
\hline 0.05 & 0.02 (NP-I) & 0.3783 & 1.015 & 0.9998 & 0.5654 & 0.952 & 0.9999 \\
\hline 0.05 & 0.05 (NP-I) & 0.567 & 0.935 & 0.9999 & 0.6032 & 0.942 & 0.9999 \\
\hline 0.05 & 0.1 (NP-I) & 0.4973 & 0.968 & 0.9999 & 0.5813 & 0.962 & 0.9998 \\
\hline
\end{tabular}


S. Afr. J. Chem., 2016, 69, 113-123,

$<$ http://journals.sabinet.co.za/sajchem/>.
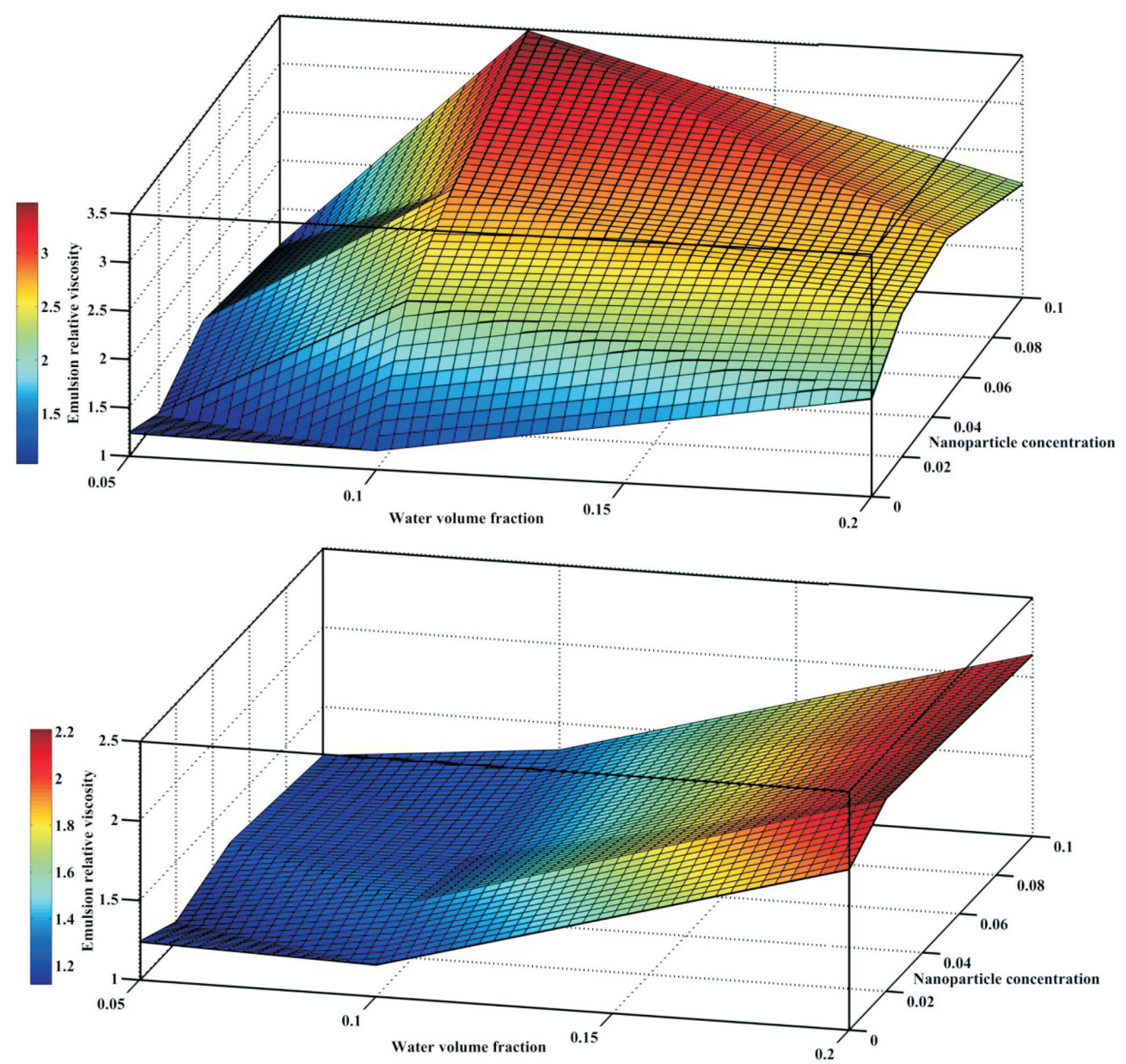

Figure 2 Effects of NP-I and NP-II concentration on the relative viscosity of water-in-oil emulsion on thefirst day: (top) NP-I; (bottom) NP-II.
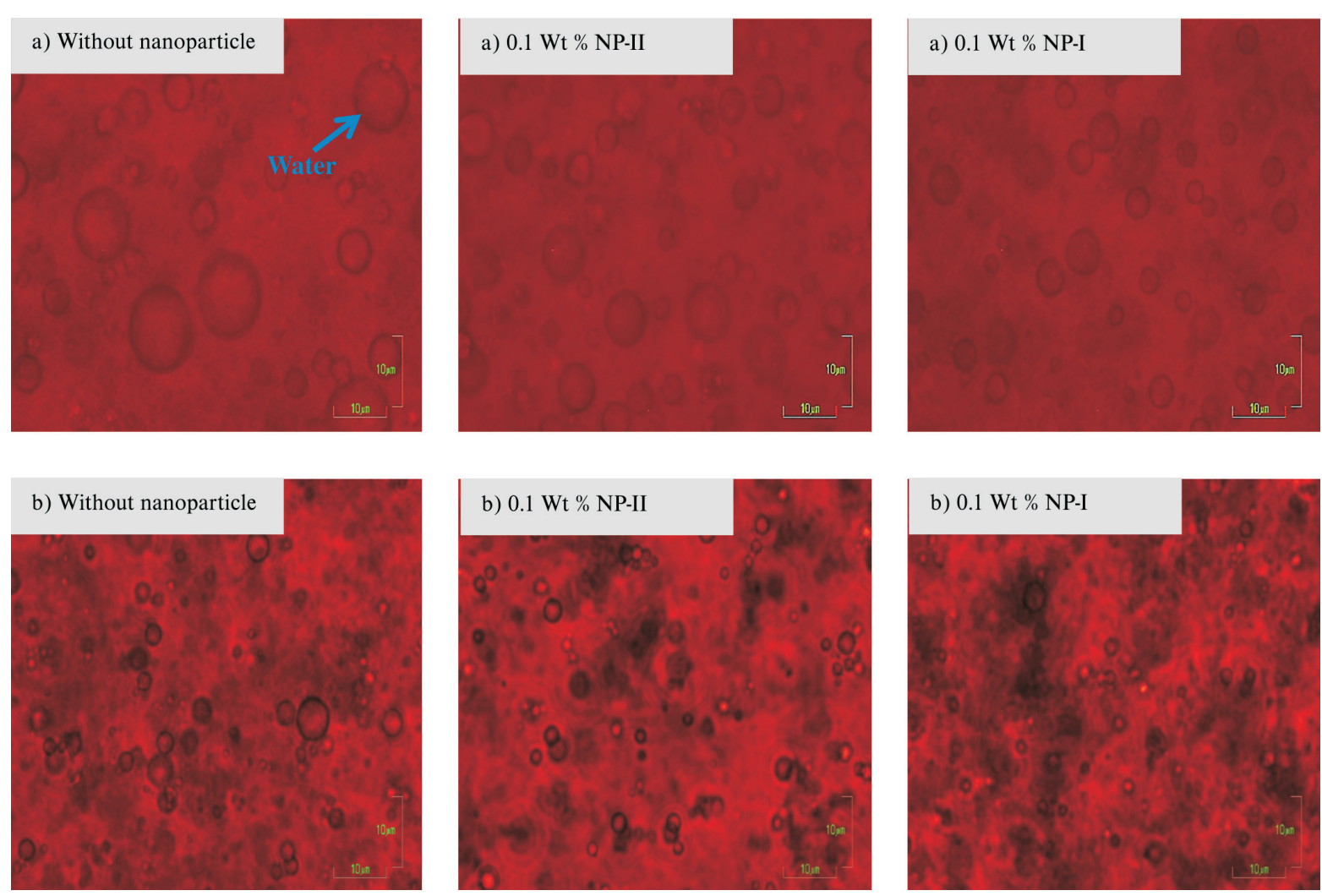

Figure 3 Photomicrographs of the effects of nanoparticle on water-in-oil emulsions at water volume fraction of $20 \%$ : (a) fresh emulsion; (b) aged emulsion. 
Table 6 Mean droplet diameter of water-in-oil emulsion at different water volume fractions and nanoparticle concentrations.

\begin{tabular}{|c|c|c|c|}
\hline \multirow{2}{*}{$\begin{array}{l}\text { Water volume } \\
\text { fractions }\end{array}$} & \multirow{2}{*}{$\begin{array}{l}\text { Nanoparticles concentration } \\
\qquad / \mathrm{wt} \%\end{array}$} & \multicolumn{2}{|c|}{ Mean droplet diameter/ $\mu \mathrm{m}$} \\
\hline & & Fresh emulsion & Aged emulsion \\
\hline 0.2 & 0 & 5.68 & 3.32 \\
\hline 0.2 & $0.02(\mathrm{NP}-\mathrm{II})$ & 5.15 & 3.3 \\
\hline 0.2 & 0.05 (NP-II) & 4.3 & 2.8 \\
\hline 0.2 & 0.1 (NP-II) & 4.2 & 2.3 \\
\hline 0.2 & $0.02(\mathrm{NP}-\mathrm{I})$ & 4.98 & 2.26 \\
\hline 0.2 & 0.05 (NP-I) & 4.52 & 2.21 \\
\hline 0.2 & 0.1 (NP-I) & 4.11 & 1.92 \\
\hline 0.1 & 0 & 4.77 & 2.76 \\
\hline 0.1 & 0.02 (NP-II) & 4.7 & 2.56 \\
\hline 0.1 & 0.05 (NP-II) & 4.4 & 2.39 \\
\hline 0.1 & 0.1 (NP-II) & 3.5 & 2.11 \\
\hline 0.1 & $0.02(\mathrm{NP}-\mathrm{I})$ & 4.6 & 2.14 \\
\hline 0.1 & 0.05 (NP-I) & 3.8 & 2.11 \\
\hline 0.1 & 0.1 (NP-I) & 3.5 & 2.01 \\
\hline 0.05 & 0 & 4.5 & 1.44 \\
\hline 0.05 & 0.02 (NP-II) & 4 & 1.3 \\
\hline 0.05 & 0.05 (NP-II) & 3.58 & 1.2 \\
\hline 0.05 & 0.1 (NP-II) & 3.1 & 1.11 \\
\hline 0.05 & $0.02(\mathrm{NP}-\mathrm{I})$ & 3.98 & 1.41 \\
\hline 0.05 & 0.05 (NP-I) & 3.06 & 1.13 \\
\hline 0.05 & $0.1(\mathrm{NP}-\mathrm{I})$ & 2.27 & 1.0075 \\
\hline
\end{tabular}

for emulsion relative viscosity correlations. Barnea and Mizrahi's correlation (exponential model) is the worst correlation for emulsion viscosity prediction, while Mooney's correlation (exponential model) has given the best results for these emulsions among the mentioned correlations. Three of the most precise correlations, including Choi-Schowalter, Guth-Simha, and Mooney, were chosen to visualize the veracity and performance of these correlations. Error distributions of Choi-Schowalter, Guth-Simha, and Mooney's correlations as a function of water volume fraction and nanoparticle concentration are illustrated in Fig. 6. Error distributions of Choi-Schowalter, Eilers, and this study's correlations showed lower relative error at lower water volume fraction. As can be observed, these correlations provided the least scattering around the zero error line for the solid-free emulsions. By calculating the value of percentage relative error for the existing models (linear, exponential, and power), it was found that all the models could not very well fit the data. In other words, these models overestimated the relative viscosity; thus, the new model development was required, which included temperature, solid concentration, and solid type.
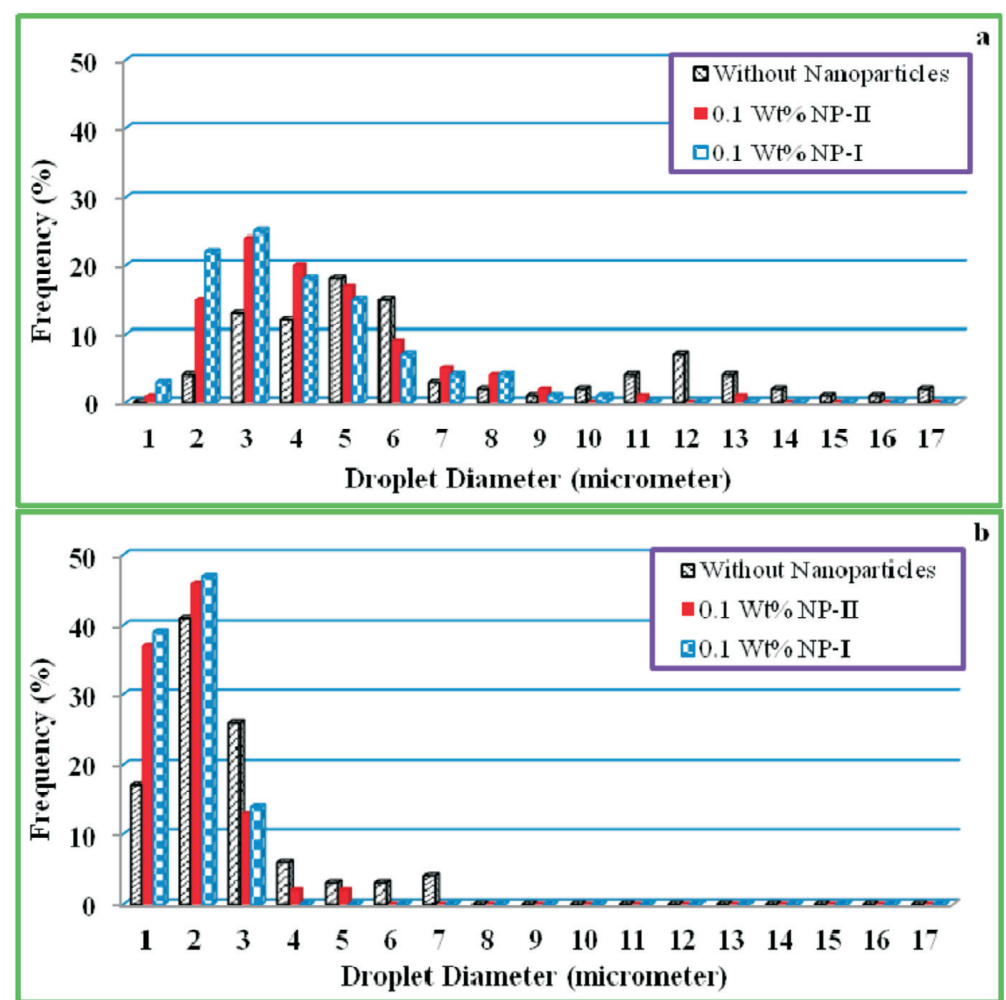

Figure 4 Droplet size distribution of water-in-oil emulsions containing $20 \%$ water cut: a) Fresh emulsion; b) Aged emulsion. 
Table 7 Analysis of variance for the experimental data.

\begin{tabular}{lccccc}
\hline \multirow{2}{*}{ Source } & \multicolumn{2}{c}{ Standard deviation } & & \multicolumn{2}{c}{$P$-value } \\
& Fresh emulsion & Aged emulsion & & Fresh emulsion & Aged emulsion \\
\hline A-Water volume fraction & 0.16 & 0.96 & & 0.0049 & 0.0143 \\
B-Type of vanoparticle & 1.11 & 0.21 & & 0.2793 & 0.0293 \\
C-Nanoparticle concentration & 0.56 & 2.13 & & 0.0488 & 0.2713 \\
AB & 0.52 & 0.45 & 0.0426 & 0.0299 \\
AC & 2.98 & 3.18 & & 0.4359 & 0.6549 \\
BC & 3.33 & 2.71 & 0.6559 & 0.4313 \\
\hline
\end{tabular}

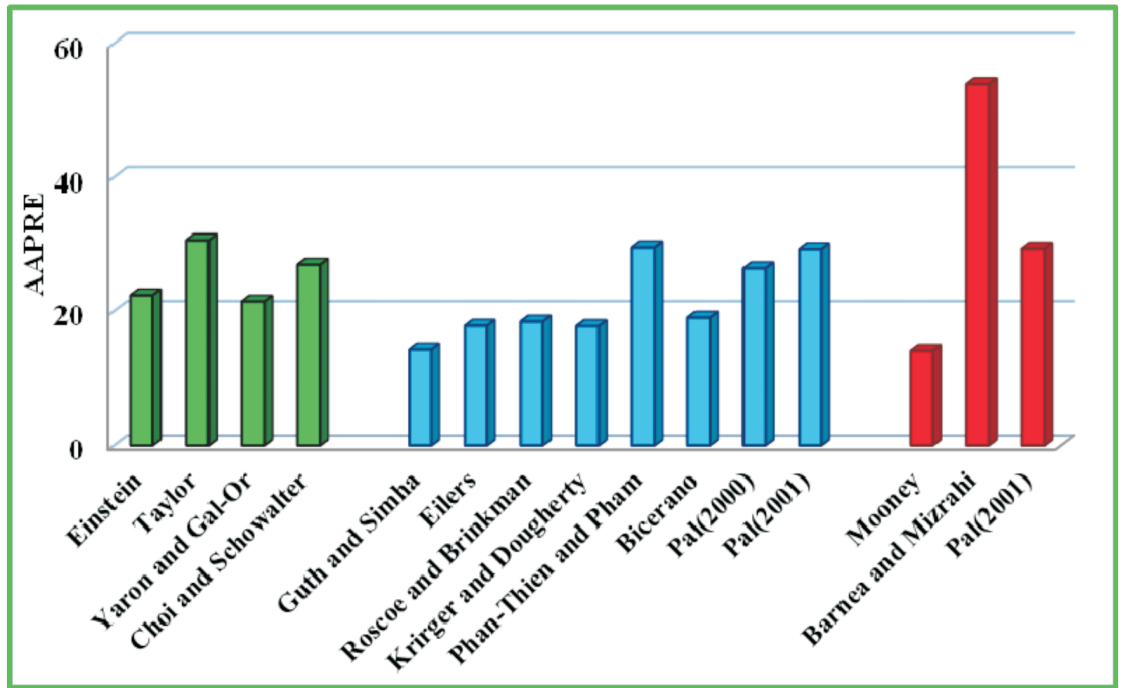

Figure 5 Average of absolute percentage relative error for emulsion's relative viscosity correlations.

\subsubsection{Effect of the Aging of Emulsions}

During this study, it was found that aging has a significant influence on the rheological behaviour of nanoparticles' stabilized emulsions. Therefore, in this part, the effect of aging on the rheological properties of such emulsions after about $100 \mathrm{~h}$ of aging at $65^{\circ} \mathrm{C}$ will be presented.For up to $100 \mathrm{~h}$, the solidstabilized emulsion with NP-I and NP-II showed no sign of destabilization, but large water droplet sediment at the bottom of the graduated cylinder. Figure 7 clarifies the water droplet of the solid-stabilized emulsion at the bottom of the graduated cylinder. This figure displays the water droplets of the emulsion stabilized by NP-I were smaller than the one by NP-II. Figure 8 shows the effects of nanoparticle and water volume fraction on the volume of sediment water. The results demonstrated the sediment water of aged emulsion increments with increasing water volume fraction. Additionally, the volume of sediment water decreased with nanoparticle concentration. Furthermore, NP-I stabilized the emulsion better than NP-II, because the sedi-
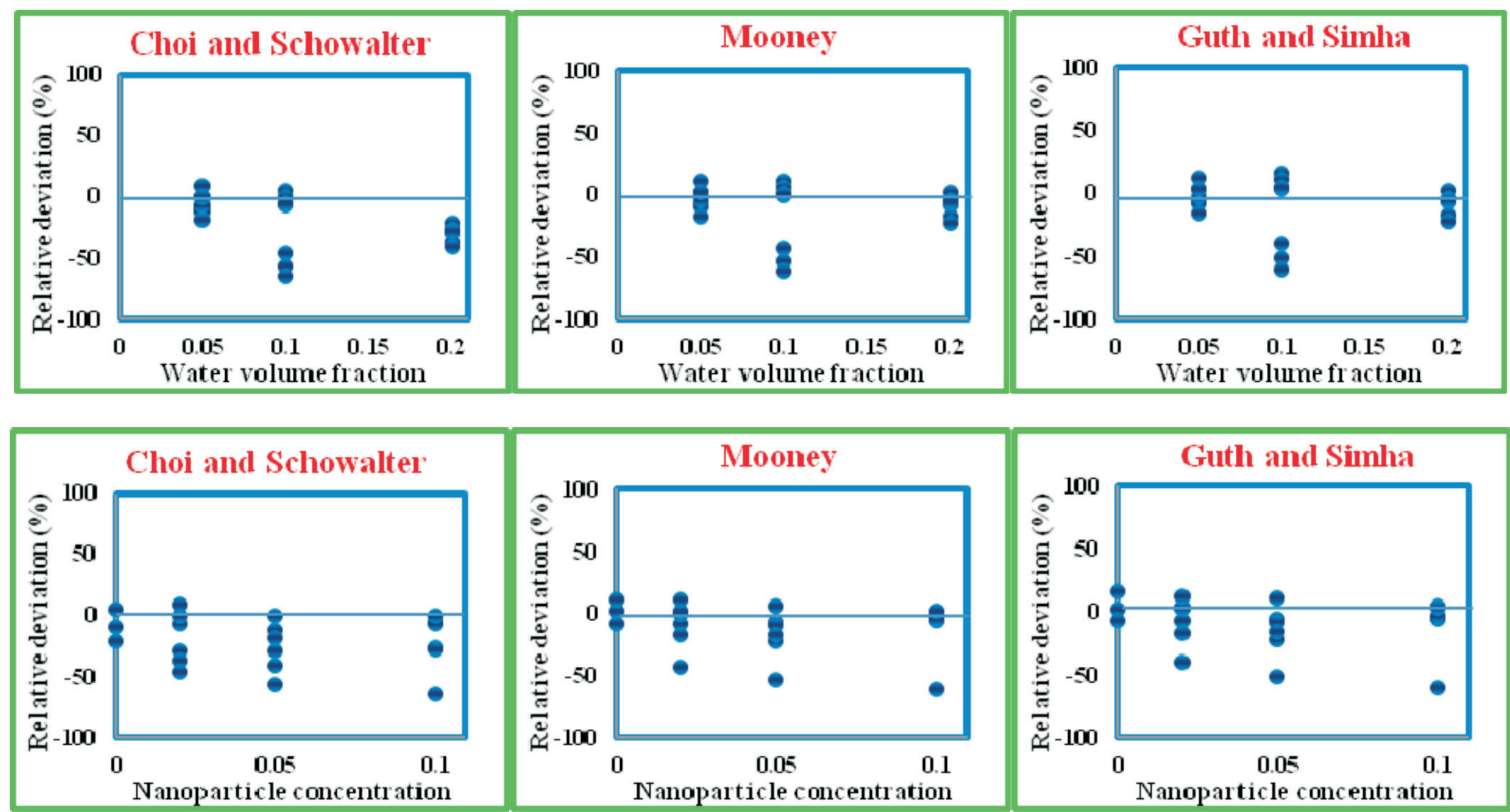

Figure 6 Percentage relative error distribution for emulsion's relative viscosity correlations. 

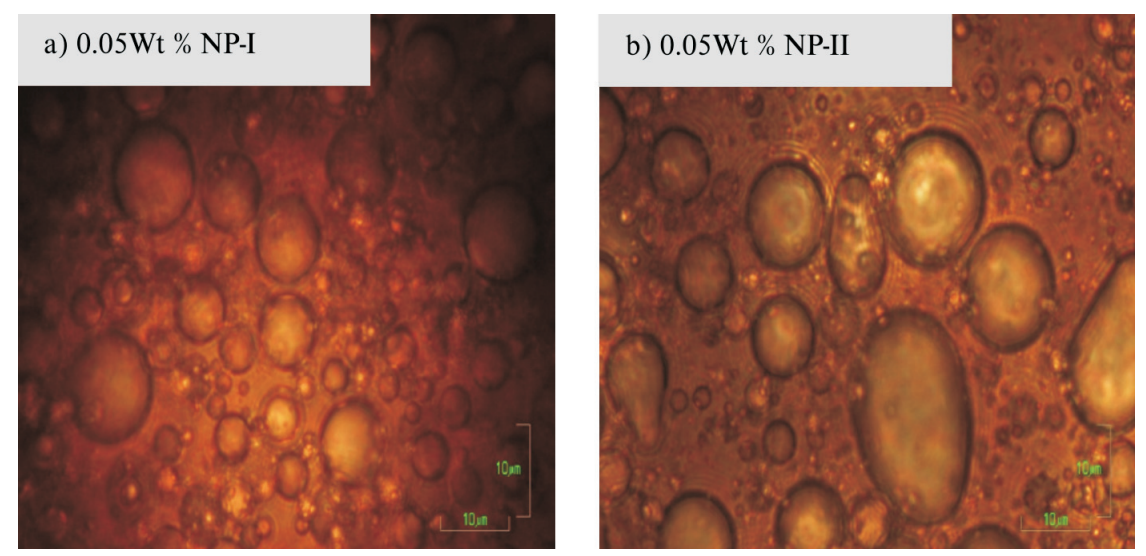

Figure 7 Water droplet of solid-stabilized emulsion at the bottom of the graduated cylinder (water volume fraction of $20 \%$ ).

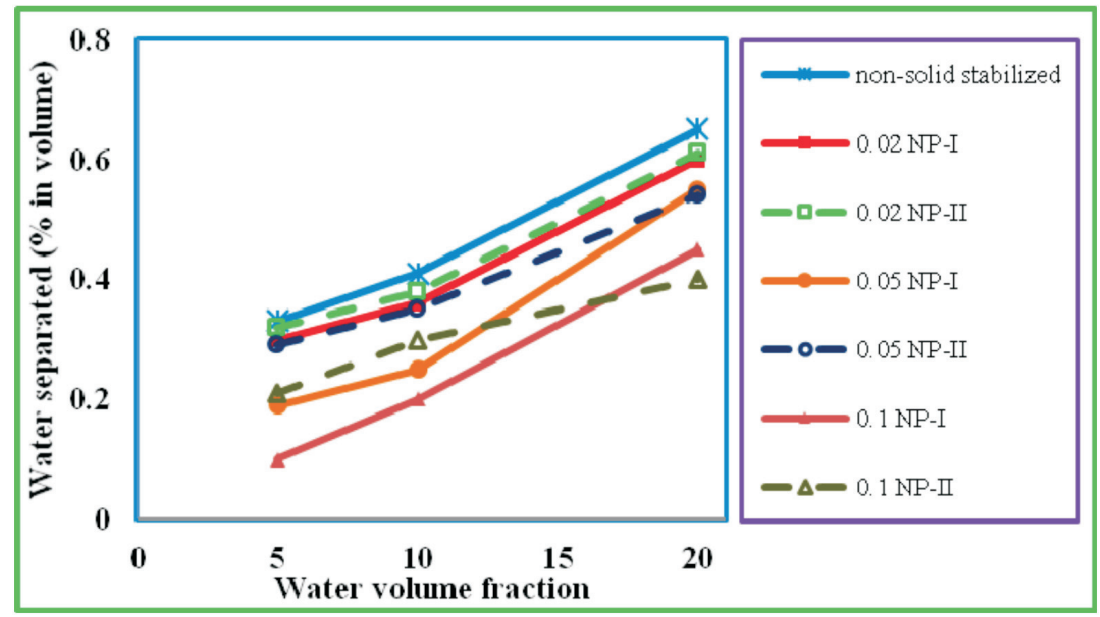

Figure 8 Effects of water volume fraction and nanoparticle on water volume separated from the aged emulsion.

ment-water volume of NP-I was lower than NP-II.

The rheological model (Equation 1) was used to analyze the experimental data. The calculated parameters of the Power Law model (Equation 1) at $20^{\circ} \mathrm{C}$ are reported in Table 5. According to these results, all the samples had a Newtonian behaviour, except the followings:

- Emulsions with the water volume fraction of $10 \%$ stabilized by $0,0.02,0.05$, and $0.1 \mathrm{wt} \%$ NP-I and NP-II,

- Emulsions with the water volume fraction of $5 \%$ stabilized by NP-I.

In other words, with increasing water volume fraction and nanoparticle concentration, the behaviour of the aged emulsion changed from Newtonian to non-Newtonian. Figure 9 shows the relations between the relative viscosity of different waterin-oil emulsions at different concentrations of NP-I and NP-II. The emulsion with the nanoparticle concentration of $0.02 \mathrm{wt} \%$ NP-I had higher viscosity than the others. From the comparison of Figs. 2 and 9, it can be pointed out that, at high water cut, the viscosity of water-in-oil emulsions (both with and without nanoparticles) appeared to decrease with aging time.

The results of the statistical tests (ANOVA) for the aged emulsion are summarized in Table 7. It can be observed that the water volume fraction, type of nanoparticle, and the combination of water volume fraction and type of nanoparticle had a significant effect $(P<0.05)$ on the emulsion viscosity.

From the photomicrographs of Fig. 3a (fresh emulsion) and Fig. $3 b$ (aged emulsion), it is obvious that the droplet size of the emulsion after about $100 \mathrm{~h}$ of aging was considerably smaller than that on the first day of emulsion. Table 6 demonstrates the mean droplets diameter of the aged emulsion. Also, Table 6 shows the effect of aging and nanoparticle concentration on water droplets' mean diameter. It can be observed that the aged emulsions had a smaller droplet diameter because of large water droplet sedimentation. Furthermore, with increasing nano-particle concentration, the average droplets diameter decreased. Figure $4 \mathrm{~b}$ depicts the corresponding droplet size distribution for the water-in-oil emulsions. Comparison of Fig. $4 \mathrm{a}$ and Fig. $4 \mathrm{~b}$ highlights that, during aging, the distribution was shifted towards smaller droplet size and the number of droplets in the emulsion phase decreased. ${ }^{19}$

Comparison of the fresh and aged emulsions illustrated that the viscosity, droplet diameter, droplet size distribution, and stability of emulsions were significantly time-dependent. Water droplets coalesced to each other and formed larger droplets. The larger droplets were the precipitates at the bottom of the graduated cylinder. Consequently, the amount of water droplets in the emulsion phase was reduced and the mean droplet diameter decreased. Due to this decrement in the water droplets, the viscosity decreased. Effects of nanoparticle concentration decreased after $100 \mathrm{~h}$, because the amount of the used nanoparticle was very low and also, in some cases, the particles stuck to each other.

\section{Conclusion}

In this study, the effects of nanoparticle type, nanoparticle concentration, and water volume fraction on the rheology of water-in-oil emulsion were experimentally and theoretically investigated. Based on the experimental results of this study and their statistical analysis, the Power Law model can be used for predicating therheological behaviour of crude oil, nanoparticles 

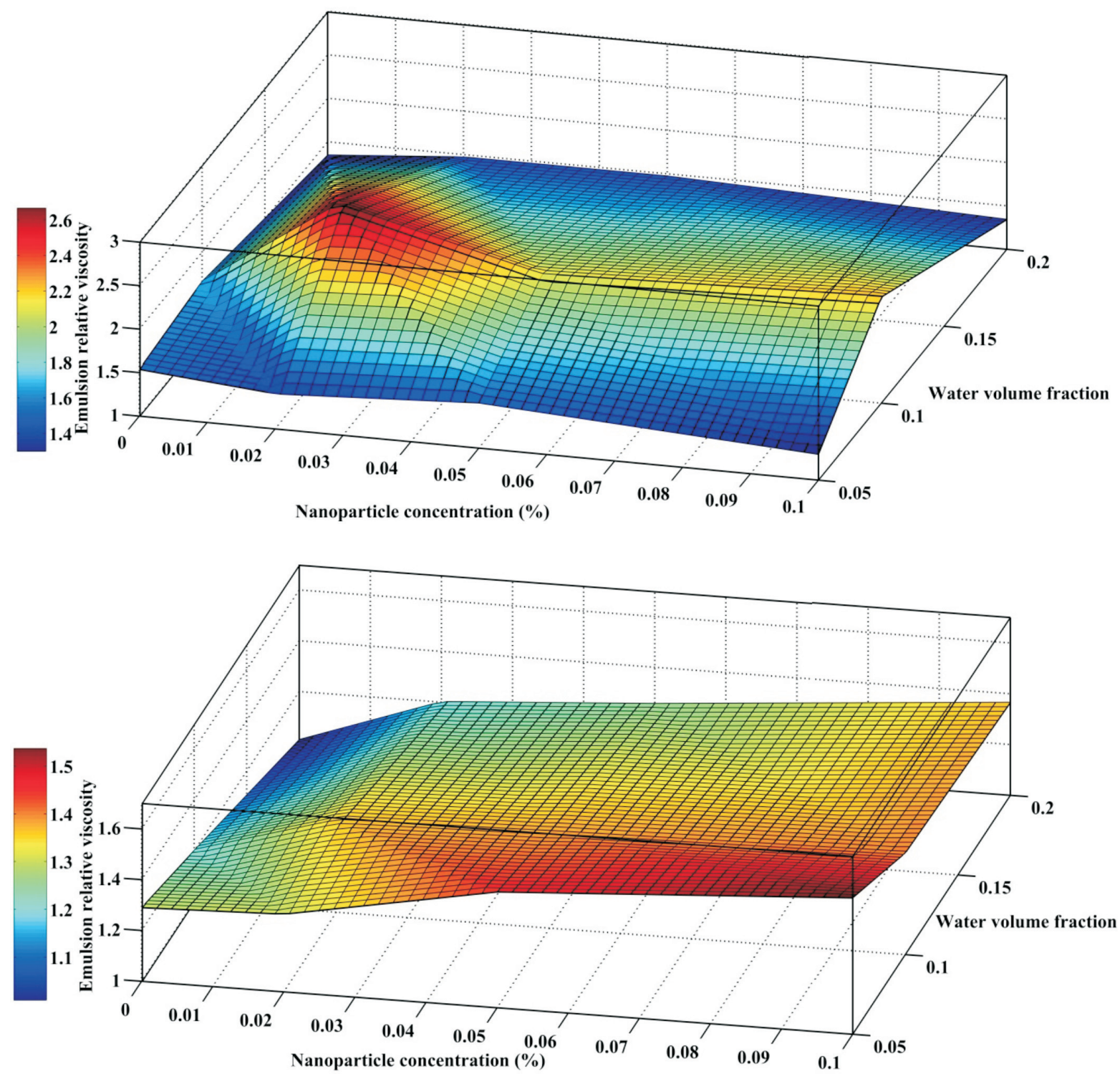

Figure 9 Effects of NP-I and NP-II concentrations on the relative viscosity of water-in-oil emulsion on the fourth day: (top) NP-I; (bottom) NP-II.

suspensions in crude oil, and water-in-oil emulsions. The viscosity and droplet size of the water-in-oil emulsions were influenced by the amount and type of nanoparticles, volume of water fraction, and aging time of emulsion. The droplet size of the emulsions decreased with the addition of nanoparticles and increase of aging times.

Fifteen correlations for the relative viscosity of solid-free and solid-stabilized emulsions were evaluated through statistical and graphical error analyses. These correlations failed to take into account the nanoparticle concentration and the results showed the inaccuracy of these correlations. The use of models by Einstein, Taylor, Yaron and Gal-Or, Choi and Schowalter, Guth and Simha, Eilers, Roscoe, and Brinkman, Krirger and Dougherty, Phan-Thien and Pham, Bicerano, Pal, Mooney, Barnea and Mizrahi for the prediction of the apparent viscosity of emulsions is limited. These models provide acceptable results only for the emulsions without nanoparticles.

\section{Statistical Quantities}

Average percentage relative error:

$r=\frac{1}{n} \sum_{i=1}^{n} E_{i}, E_{i}=\left[\frac{\left(\eta_{r}\right)_{\text {exp }}-\left(\eta_{r}\right)_{e s t .}}{\left(\eta_{r}\right)_{\text {exp. }}}\right] \times 100 \Rightarrow i=1,2,3, \ldots, n$
Average absolute percentage relative error:

$E_{a}=\frac{1}{n} \sum_{i=1}^{n}\left|E_{i}\right|$

$R^{2}=1-\frac{\sum_{i=1}^{n}\left(X_{i_{\ldots \ldots}}-X_{i_{\ldots .}}\right)^{2}}{\sum_{i=1}^{n}\left(X_{i_{\text {ant }}}-\operatorname{average}\left(X_{\ldots-\ldots}\right)\right)^{2}}$

\section{Nomenclature}

The following symbols are used in this paper:

$r$ [m] Radius

$m \quad[-] \quad$ Consistency index

$n \quad[-] \quad$ Flow behaviour index

K [-] Ratio of dispersed phase viscosity to the

continuous phase viscosity

$k \quad[-] \quad$ Constant parameter

$R^{2} \quad[-] \quad$ Regression correlation coefficient

$X \quad[-] \quad$ Generic dependent variable

Greek Symbols

$\eta \quad[\mathrm{Pa} . \mathrm{S}] \quad$ Viscosity

$\eta_{\mathrm{r}} \quad[-] \quad$ Relative viscosity

$\phi \quad[\%] \quad$ Dispersed phase volume fraction 


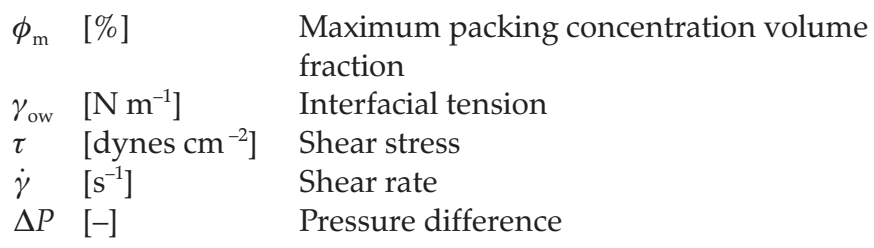

\section{References}

1 S. Thomas and S. Farouq Ali, Flow of emulsions in porous media, and potential for enhanced oil recovery, Petrol. Sci. Technol., 1989, 3, 121-136.

2 H. Alboudwarej, M. Muhammad, A. K. Shahraki, S. Dubey, L. Vreenegoor, J. M. Saleh, Rheology of heavy-oil emulsions, SPE Prod.Oper., 2007, 22, 285-293.

3 S. Keleşoğlu, B.H. Pettersen and J. Sjöblom, Flow properties of water-in-North Sea heavy crude oil emulsions, J. Petrol. Sci. Eng., 2012, $100,14-23$.

4 A.I. Anisa and A.H. Nour, Affect of viscosity and droplet diameter on water-in-oil (w/o) emulsions: an experimental study, World Acad. Sci. Eng. Technol., 2010, 62, 692-694.

5 J. Weiss, and G. Muschiolik, Factors affecting the droplet size of water-in-oil emulsions (w/o) and the oil globule size in water-in-oil-in-water emulsions (W/O/W), J. Disp. Sci. Technol., 2007, 28, 703-716.

6 M.B. Sadeghi, A. Ramazani S. A, V. Taghikhani and C. Ghotbi, Experimental investigation of rheological and morphological properties of water in crude oil emulsions stabilized by a lipophilic surfactant, J. Disp. Sci. Technol., 2013, 34, 356-368.

7 K. Salam, A. O. Alade, A. O. Arinkoola and A. Opawale, Improving the demulsification process of heavy crude oil emulsion through blending with diluent, J. Petrol. Eng., 2013, 2013.

8 J.R. Bragg and R. Varadaraj, USA Patent US 5,910,467 A, 2006

9 R. Varadaraj, J. R. Bragg, D. G. Peiffer and C. W. Elspass, USA Patent US 7,186,673 B2, 2007.

10 M. Fanun, Microemulsions: properties and applications, CRC Press, Boca Raton 2010.

11 D. Clausse, D. Daniel-David, F. Gomez, L. Komunjer, I. Pezron, C. Dalmazzone and C. Noïk, Emulsion stability and interfacial properties-application to complex emulsions of industrial interest, in Colloid Stability and Application in Pharmacy, (T.F. Tandros, ed.), vol. 3, Wiley-VCH Verlag, 2007, pp. 119-149.

12 N.N.Tshilumbu, E. Kharatyan, and I. Masalova, Effect of nanoparticle hydrophobicity on stability of highly concentrated emulsions, J. Disp. Sci. Technol., 2014, 35, 283-292.

13 B.P. Binks, J.H. Clint and C.P. Whitby, Rheological behavior of water-in-oil emulsions stabilized by hydrophobic bentonite particles, Langmuir, 2005. 21, 5307-5316.

14 S. Simon, S. Theiler, A. Knudsen, G. Øyea and J. Sjöblom, Rheological properties of particle-stabilized emulsions, J. Disp. Sci. Technol., 2010. 31, 632-640.

15 A. Hemmati-Sarapardeh, M. Khishvand, A. Naseri and A.H. Mohammadi, Toward reservoir oil viscosity correlation, Chem. Eng. Sci., 2013, 90, 53-68.

16 A. Hemmati-Sarapardeh, S.M.J Majidi, B. Mahmoudi, A. Ramazani S.A. and A.H. Mohammadi, Experimental measurement and modeling of saturated reservoir oil viscosity, Korean J. Chem. Eng., 2014, 31, 1253-1264.

17 A. Hemmati-Sarapardeh, A. Shokrollahi, A. Tatar, F. Gharagheizi, A. H. Mohammadi and A. Naseri, Reservoir oil viscosity determination using a rigorous approach, Fuel, 2014, 116, 39-48.

18 J. Zhang, J. Xua, M. Gao and Y. Wua, Apparent viscosity of oil-water (coarse) emulsion and its rheological characterization during the phase inversion region, J. Disp. Sci. Technol., 2013, 34, 1148-1160.

19 D.C. Maia Filho, J.B.V.S. Ramalho, L.S. Spinelli and E.F. Lucas, Aging of water-in-crude oil emulsions: effect on water content, droplet size distribution, dynamic viscosity and stability, Colloids Surf., A, 2012, 396, 208-212.

20 E.E. Johnsen and H.P. Rønningsen, Viscosity of 'live' water-in-crude- oil emulsions: experimental work and validation of correlations, $J$. Disp. Sci. Technol., 2003, 38, 23-36.

$21 \mathrm{M}$. Andresen and P. Stenius, Water-in-oil emulsions stabilized by hydrophobized microfibrillated cellulose, J. Disp. Sci. Technol., 2007, 28, 837-844.

22 B. Abedi, M.H. Ghazanfari and R. Kharrat, Experimental study of polymer flooding in fractured systems using five-spot glass micromodel: the role of fracture geometrical properties, Energ. Explor. Exploit., 2012, 30, 689-706.

23 Y. Yan, , R. Pal and J. Masliyah, Rheology of oil-in-water emulsions with added solids, Chem. Eng. Sci., 1991, 46, 985-994.

24 B.Yaghi, M. Benayoune and A. Al-Bemani, Viscosity of water-oil emulsions with added nano-size particles, J. Pet. Sci. Technol., 2001, 19, 373-386.

25 B.Yaghi, Rheology of oil-in-water emulsions containing fine particles, J. Pet. Sci. Technol., 2003, 40, 103-110.

26 S. Keleşoğlu, B.H. Pettersen and J. Sjöblom, Characterization of water-in-North Sea acidic crude oil emulsions by means of rheology, droplet size, and laminar flow in pipeline, J. Disp. Sci. Technol., 2012. $33,536-548$.

27 T. Sharma, G.S. Kumar and J.S. Sangwai, Viscoelastic properties of oil-in-water $(\mathrm{o} / \mathrm{w})$ Pickering emulsion stabilized by surfactant-polymer and nanoparticle-surfactant-polymer systems, Ind. Eng. Chem. Res., 2015. 54, 1576-1584.

28 M.S. Karambeigi, R. Abbassi, E. Roayaei and M.A. Emadi, Emulsion flooding for enhanced oil recovery: interactive optimization of phase behavior, microvisual and core-flood experiments, Ind. Eng. Chem., 2015, 29, 382-391.

29 A. Einstein, A new determination of molecular dimensions, Ann. Phys., 1906, 19, 289-306.

30 G.I. Taylor , The viscosity of a fluid containing small drops of another fluid, Proc. R. Soc. London, Ser. A, 1932, 138, 41-48.

31 I. Yaron and B. Gal-Or, On viscous flow and effective viscosity of concentrated suspensions and emulsions, Rheol. Acta, 1972, 11, 241-252.

32 S.J. Choi and W. Schowalter, Rheological properties of nondilute suspensions of deformable particles, Phys. Fluids A, 1975, 18, 420-427.

33 E. Guth and R. Simha, Untersuchungen über die viskosität von suspensionen und lösungen. 3. über die viskosität von kugelsuspensionen, Colloid. Polym. Sci., 1936, 74, 266-275.

34 v.H. Eilers, Die viskosität von emulsionen hochviskoser stoffe als funktion der konzentration, Colloid. Polym. Sci., 1941, 97, 313-321.

$35 \mathrm{R}$. Roscoe, The viscosity of suspensions of rigid spheres, Br. J. Appl. Phys., 1952, 3, 267.

$36 \mathrm{H}$. Brinkman, The viscosity of concentrated suspensions and solutions, J. Chem. Phys., 1952, 20, 571-571.

37 I.M. Krieger and T.J. Dougherty, A mechanism for non-Newtonian flow in suspensions of rigid spheres, JOR, 1959, 3, 137-152.

38 N. Phan-Thien and D. Pham, Differential multiphase models for polydispersed suspensions and particulate solids, J. Non-Newtonian Fluid Mech., 1997, 72, 305-318.

39 J. Bicerano, J.F. Douglas and D.A. Brune, Model for the viscosity of particle dispersions, J. Macromol. Sci., 1999, 39, 561-642.

40 R. Pal, Viscosity-concentration equation for emulsions of nearly spherical droplets, J. Colloid Interface Sci., 2000, 231, 168-175.

41 R. Pal, Novel viscosity equations for emulsions of two immiscible liquids, JOR, 2001, 45, 509-520.

$42 \mathrm{M}$. Mooney, The viscosity of a concentrated suspension of spherical particles, J. Colloid Sci., 1951, 6, 162-170.

43 E. Barnea and J. Mizrahi, On the "effective" viscosity of liquid-liquid dispersions, Ind. Eng. Chem. Fundam., 1976, 15, 120-125.

44 R. Pal, , Effect of droplet size on the rheology of emulsions, AIChE J., 1996, 42, 3181-3190.

45 A. Drelich, F. Gomez, D. Clausse and I. Pezron, Evolution of waterin-oil emulsions stabilized with solid particles: influence of added emulsifier, Colloids Surf., A, 2010, 365, 171-177.

46 D.C. Montgomery, Design and Analysis of Experiments, vol. 7, Wiley, New York, 1984 